\title{
Altered heart rate and blood pressure variability in mice lacking the Mas protooncogene
}

T. W alther ${ }^{1}$, N. Wessel ${ }^{3}$, N. Kang ${ }^{1}$, A. Sander ${ }^{3}$, C. Tschöpe2, H. Malberg3, M. Bader ${ }^{1}$ and A. Voss ${ }^{3}$
${ }^{1}$ M ax-D elbrück-Center for Molecular M edicine (MDC), and

${ }^{2}$ Department of Cardiology and Pneumology,

University Hospital Benjamin Franklin, Free University of Berlin,

Berlin, Germany

${ }^{3} U$ niversity of Applied Sciences, Jena, Germany

\section{Correspondence \\ T. Walther \\ Max-Delbrück-Center for \\ Molecular Medicine (MDC) \\ Robert-Rössle-Str. 10 \\ D-13092 Berlin-Buch \\ Germany \\ Fax: +49-30-9406-2110 \\ E-mail: thowal@mdc-berlin.de \\ Presented at the XIII Annual M eeting of the Federação de Sociedades de Biologia Experimental, Caxambu, MG, Brasil, August 26-29, 1998.}

Received July 26, 1999 Accepted September 16, 1999

\section{Abstract}

Heart rate variability is a relevant predictor of cardiovascular risk in humans. A significant genetic influence on heart rate variability is suggested, although the genes involved are ill-defined. The Masprotooncogene encodes a G-protein-coupled receptor with seven transmembrane domains highly expressed in testis and brain. Since this receptor is supposed to interact with the signaling of angiotensin II, which is an important regulator of cardiovascular homeostasis, heart rate and blood pressure were analyzed in Mas-deficient mice. Using a femoral catheter the blood pressure of mice was measured for a period of $30 \mathrm{~min}$ and 250 data values per second were recorded. The mean values and range of heart rate and blood pressure were then calculated. Neither heart rate nor blood pressure were significantly different between knockout mice and controls. However, high resolution recording of these parameters and analysis of the data by non-linear dynamics revealed significant alterations in cardiovascular variability in Mas-deficient animals. In particular, females showed a strong reduction of heart rate variability. Furthermore, the data showed an increased sympathetic tone in knockout animals of both genders. The marked alterations detected in Mas-deficient mice of both genders suggest that the Mas-protooncogene is an important determinant of heart rate and blood pressure variability.

\section{Introduction}

Blood-pressure variability (BPV) and heart-rate variability (HRV) are generated by the rhythmic actions of cardiovascular hormones and neuronal pathways on effector organs such as heart, kidney, and blood vessels. HRV has been shown to be a relevant predictor for the mortality of patients
Key words

- Blood pressure variability

- Heart rate variability

- Baroreflex sensitivity

- Mas protooncogene with myocardial infarction. The association of a higher risk for post-infarction mortality with reduced HRV was first shown by Wolf et al. (1). The clinical importance of HRV was confirmed in several studies since the late 1980s. HRV was shown to be a strong and independent predictor of mortality following acute myocardial infarction (2-7). However, the molecular mechanisms in- 
volved in the regulation of these variabilities are only poorly understood. The brain is the source for most of the signals believed to be responsible for the setting of blood pressure (BP) and heart rate (HR). Moreover, HRV was impaired by ischemic damage to the brain caused by stroke (8). Therefore, genes involved in cardiovascular regulation and expressed in the central nervous system should be interesting candidates for the molecular genetic analysis of BPV and HRV.

In addition to being expressed in the testes, the Mas protooncogene (9) is mainly expressed in the brain, where its mRNA has been located in the hippocampus, dentate gyrus, piriform cortex and amygdala (1012). In addition, Mas-mRNA was detected in low concentrations in kidney and heart $(12,13)$. Functional studies have suggested that the Mas gene codes for an angiotensin II (AngII)-sensitive G-protein-coupled receptor (14). However, the increase of intracellular $\mathrm{Ca}^{2+}$-concentrations in Mas-transfected cells after AngII treatment could only be confirmed in cells endogenously expressing the AngII receptor AT1 (15). Still, the exact nature of the interaction of Mas, AngII and the AT1-receptor is elusive. To elucidate the relevance of the Mas protein, we eliminated the gene in mice by gene targeting technology (16). Apart from a changed anxiety behavior, knockout animals exhibited as an outstanding feature an improved long-term potentiation (LTP) in the dentate gyrus. As AngII causes a reduction of LTP (17) the ablation of the Mas protein and the resulting decrease in AngII signaling could be an explanation for the observed stabilization of LTP. Since AngII is one of the main regulators of BP also via pathways in the central nervous system (18) we hypothesized that Mas may play a role in the regulation of $\mathrm{BP}$ and HR. To characterize this role, BP of Mas-deficient mice was recorded continuously with high time resolution. From these data we extracted HR and systolic and diastolic BP on a beat-to-beat basis. Further- more, the spontaneous baroreflex was examined by the method of Parlow et al. (19) whereby spontaneous or accidental changes in BP under normal conditions are used for the calculations as opposed to the drug-induced baroreflex measurements. This parameter is closely related to the variability of HR and BP and, therefore, can be regarded as a link between them.

\section{Material and Methods}

\section{BP measurement}

Fourteen control $(+/+)(7$ males and 7 females) and 15 knockout (-/-) mice (6 males and 9 females) were used for the experiments at 14 weeks of age. The investigation was carried out according to the Guide for the Care and Use of Laboratory Animals published by the US National Institutes of Health (NIH Publication No. 85-23, revised 1985). The animals were anesthetized with thiopental (50 ng/kg body weight) and a catheter was placed in the femoral artery. Five minutes after the end of the operation $\mathrm{BP}$ was measured for $30 \mathrm{~min}$ with a pressure transducer and a commercially available software (TSE, Bad Homburg, Germany). In addition to the normal measurement, BP was recorded at a high resolution $(250 \mathrm{~Hz}$ sampling frequency).

\section{Variability analysis of HR and BP}

By correlation analysis the beat-to-beat values for diastolic and systolic pressure as well as the interbeat intervals (HR) were extracted from the continuous BP signal. To achieve this, a pattern (window of $80 \mathrm{~ms}$ duration of a chosen systolic BP parameter, i.e., $40 \mathrm{~ms}$ before and $40 \mathrm{~ms}$ after the maximum peak) was shifted to the time series and the respective cross correlation was calculated. The points of maximal correlation in the given expected interval are identified as heartbeats and the systolic and diastolic BP 
is determined within physiological regions. From the resulting time series the measures of HRV are determined as far as the interbeat intervals are concerned, and in the case of the systolic and diastolic BP series the respective measures of BPV are determined.

Since arrhythmia and artifacts have a strong influence on the parameters of BPV and HRV analysis, it is necessary to exclude them from time series of variability. This exclusion is performed by an adaptive filter algorithm which takes into account the momentary basic variability. The remaining data points are $\mathrm{NN}$ intervals (NN: interval between two successive normal heartbeats). HRV and BPV series different measures were calculated from the resulting half hour. The 'meanNN' (the mean), 'sdNN' (the standard deviation) and 'shannon' (the shannon entropy of the histogram) were determined from the time domain parameters.

The following frequency domain parameters were calculated from the time series interpolated to $50 \mathrm{~ms}$ by means of Fast Fourier Transformation and a Blackman-Harriswindow: 'low frequency (lf)/high frequency (hf)', 'Ifn' (standardized lf) with 'If', the spectral power within $0.18 \mathrm{~Hz}$ to $1.0 \mathrm{~Hz}$ and 'hf', the spectral power within $1.0 \mathrm{~Hz}$ to 2.0 $\mathrm{Hz}$.

Furthermore, three further measures of non-linear dynamics were calculated from symbolic dynamics $(20,21)$. Symbolic dynamics is based on the transformation of the time series into symbols. By such transformation a part of the detailed information included in the time series is lost, but important information about dynamics within the time series remains. Depending on the chosen number of symbols and on the data length, words of different length are formed on the basis of the symbols. Figure 1 shows the transformation of the variability time series into a symbol time series. The original time series are transformed into symbols in accordance to the given definition depending on the mean ' $\mu$ ' and on the parameter ' $a$ '.
The parameter ' $a$ ' determines the permitted deviation from the mean and was set at 0.05 .

Words consisting of four symbols $\{0,1$, $2,3\}$ with the length of three were analyzed. The following parameters were extracted from the word distribution: 'fwshannon', Shannon-entropy (a well-known measure for complexity; 21); 'wpsum 13', percentage of words containing only the symbols ' 1 ' and ' 3 ' and 'wsdvar', word variability.

\section{Baroreceptor reflex}

The spontaneous baroreflex was measured by the method of Parlow et al. (19). The time series of systolic BP and HR were examined in parallel for the three following signal scores respectively, where HR is decreased while BP is increased. The number and the increase of the spontaneous changes were then recorded.

\section{Statistical methods}

Since the calculated parameters were partly not normally distributed and since normal distribution is a precondition for many statistical procedures, the parameters were initially transformed logarithmically. They were then analyzed by the KolmogorovSmirnov test for normal distribution, and

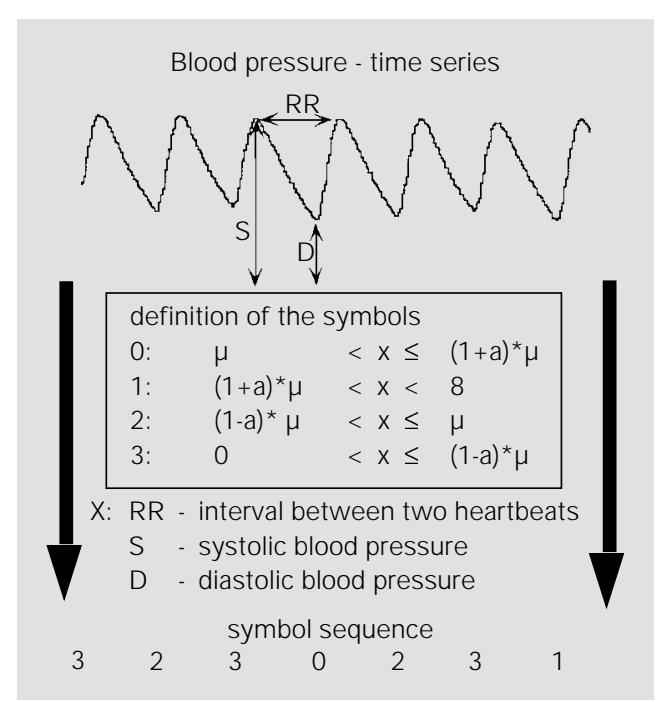

Figure 1 - The basic principle of symbolic dynamics, i.e., the transformation into symbols. For each value of the $t_{n}-t_{n-1}$ tachogram we checked which of the four conditions (definitions related to either interbeat intervals or to BP differences) was fulfilled and we replaced it with the respective symbol. From the resulting symbol sequence a word sequence of 3 words is formed. Finally, the distribution of these words is investigated. ' $\mu$ ' denotes the mean value (heart rate, systolic and diastolic pressure) and 'a' represents the chosen limit (here 0.1 ) for symbol classification. 
this hypothesis was confirmed for all parameters. Thereafter, univariate analyses of variance were performed for the separation of control animals from the knockout animals. This was done for both the whole groups and the gender-matched subgroups. The criterion for significance was $5 \%$.

To examine sex specificity, gradual discriminate analyses were applied additionally to differentiate between groups.

\section{Results}

To study the interrelation between AngII and the Mas-gene product we investigated mean BP and HR in Mas-deficient and wildtype mice. No significant differences for either parameter were found in males or females (Figure 2). Irrespective of genotype, male mice exhibited higher BP values.

Using a high resolution beat-to-beat BP record it was possible to visualize the variabilities of HR and BP for single animals. Representative BP and HR recordings of control and Mas-deficient mice of both sexes are presented graphically in Figures 3 and 4.

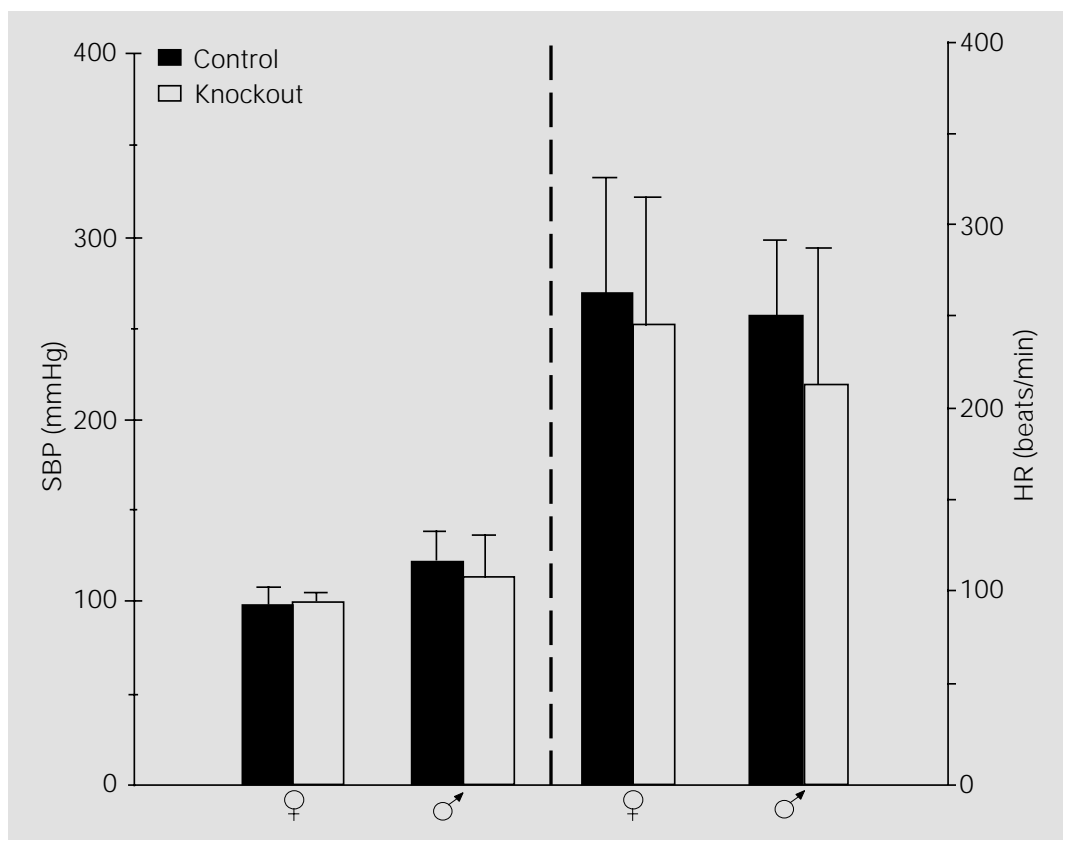

Figure 2 - Systolic blood pressure (SBP) and heart rate (HR) for control (closed bars) and Mas-deficient (open bars) mice of both genders.
The decrease in HRV was particularly visible in female knockout mice, while the increase in BVP was particularly visible in males.

These recordings were used to quantitatively analyze HR and BP variance, i.e., beat-to-beat dynamics. The extracted parameters characterizing BPV and HRV are summarized in Table 1. HRV differed between knockout and control animals in the standard procedures. A significant reduction in basic variance (sdNN, shannon) and an increase of lfn and consequently of lf/hf were observed in Mas-deficient mice.

BPV did not differ between groups apart from one non-linear parameter (fwshannon). However, the fwshannon parameter shows that an intermittent reduction of variance is connected with its increase. The shannon entropy calculated from the distributions of words 'fwshannon' is a suitable measure of the complexity of the time series. Higher values of this entropy refer to a higher complexity in the corresponding tachogram and lower values to lower ones.

The influence of gender on parameters of HRV and BPV is presented in Table 2. Here as well, the standard parameters of the time and frequency domain were significantly different in HRV. sdNN and shannon were reduced in female knockout animals, indicating a decreased basic variability. In male Mas-deficient animals, on the other hand, lfn and lf/hf were significantly increased.

Surprisingly, BPV exhibited different results. While in female animals there were no significant differences between knockout and control animals, in male animals there were highly significant differences in all parameters with the exception of the frequencyarea parameters. The basic variability ( $\mathrm{sdNN}$, shannon) was increased in knockout animals, as also were the values for lfn and lf/hf. Furthermore, the non-linear parameters showed clear changes in variance which also characterize an increase in variability.

The sex-specific differences in HRV and 
BPV between control and Mas-deficient mice were found for all animals of the respective groups. A gradual discrimination analysis provided a separation of $100 \%$ for all male animals only in terms of the parameters lfn (HRV) and sdNN (BPV). For the female animals a separation of $80 \%$ was obtained in terms of the parameters sdNN (HRV), shannon (HRV) and lf/hf (HRV).

The spontaneous baroreflex of the animals was also examined to see if the observed differences in variability are accompanied by changes in this parameter (Table 3). Apparently, there were sex-specific differences in frequency and average increase of the baroreflex between +/+ or -/- animals, which, however, did not reach statistical significance.

\section{Discussion}

The central finding of this study was the marked difference in HRV and BPV in Masdeficient mice compared to control animals, which was particularly visible when the data were analyzed according to gender. The extent of the effect is the reason why male animals of the knockout and control groups could be classified completely by discrimination analysis despite the relatively low number of animals per group and the relatively low sampling frequency $(250 \mathrm{~Hz})$ which, in combination, led to a relatively high scattering within groups. For the female animals the recognition/identification rate was $80 \%$, demonstrating the less dramatic differences between female knockout and control animals. We cannot exclude an influence of anesthesia on the measured cardiovascular phenotype since at least the heart rate itself is usually decreased under anesthetic conditions, but treatment with chloral hydrate led to the same results (data not shown). However, the differences between mice of distinct genotypes and gender were significant and should reflect the genetic differences between these animals. Since
Mas-deficient mice showed an increased anxiety-like behavior (16) measurements carried out on conscious mice may be influenced by these behavioral abnormalities.

HRV was significantly reduced in knockout animals of both sexes as shown by the parameter $\mathrm{sdNN}$ which is a measure of the dynamic status of a time series. In addition, the autonomic balance was shifted in favor of the sympathetic tone. This is indicated by the higher level of the parameter 'lfn' representing the normalized low frequency power, i.e., the frequency components in the 0.18 -
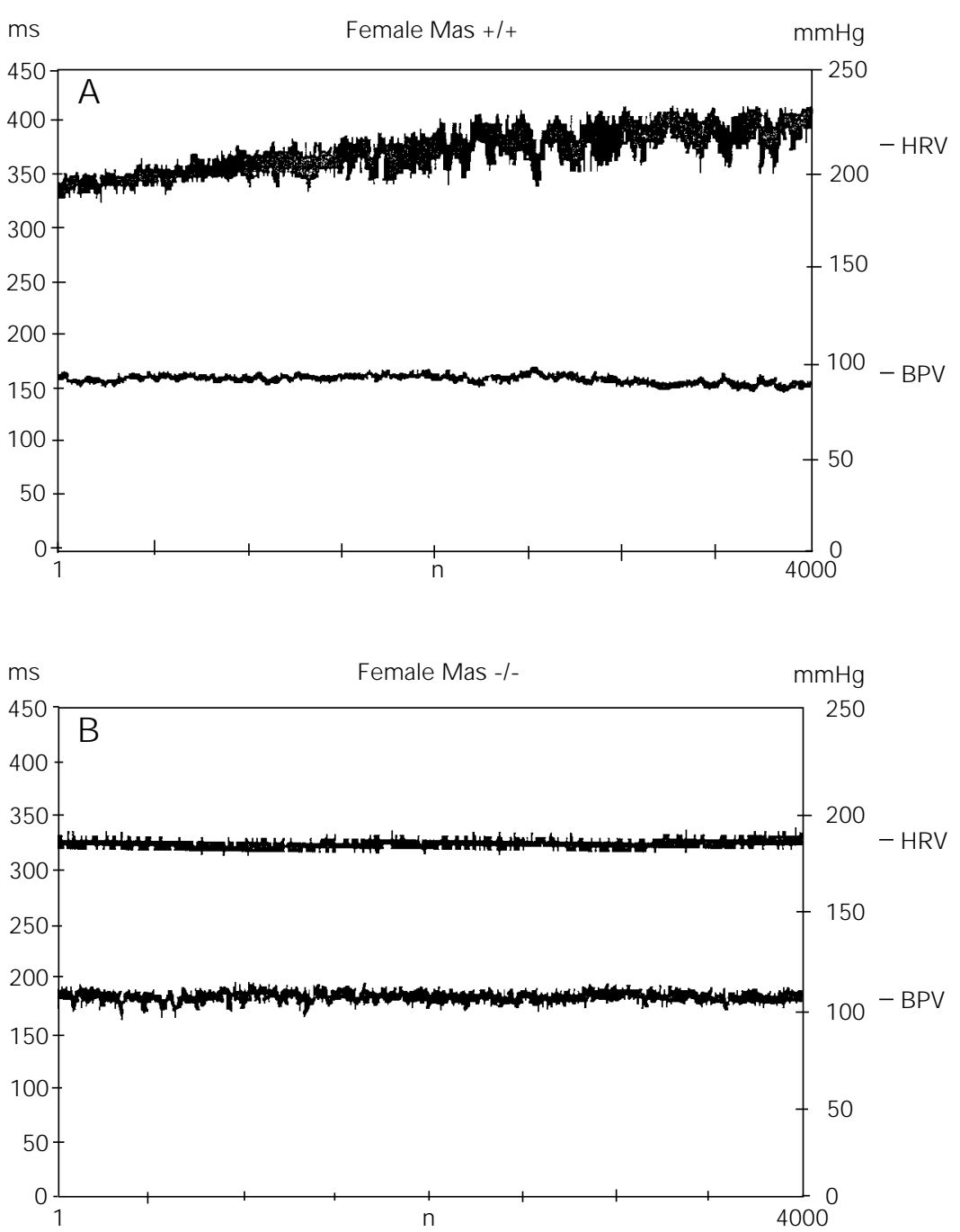

Figure 3 - Continuous measurement of heart rate (HR) in beats/min and systolic blood pressure (BP) in $\mathrm{mmHg}$ in a female wild-type (A) and a female Mas-deficient animal (B) for $16 \mathrm{~s}$. HRV and BPV, Heart rate and blood pressure variabilities, respectively. 
$1.0-\mathrm{Hz}$ band divided by the frequency components in the $0.18-2.0-\mathrm{Hz}$ band.

The BPV picture was much more complex. In an evaluation including all animals there was no difference between the knockout and the control group apart from the marker fwshannon. The higher value of fwshannon seen in Mas-deficient mice represents a higher degree of dynamics and is typical for a healthy behavior, whereas a lower value is related to pathological changes. If analysis of the data were left at this point,
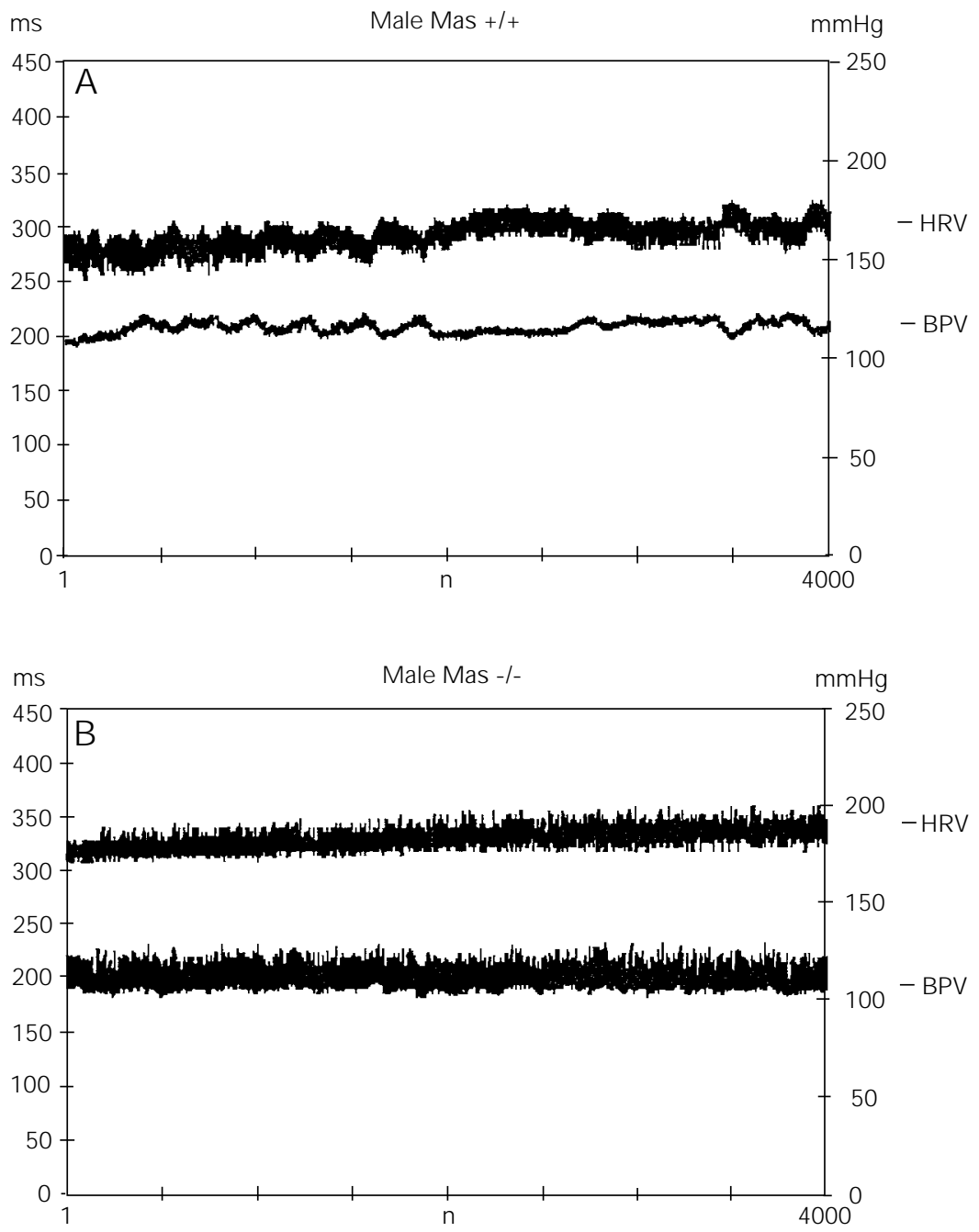

Figure 4 - Continuous measurement of heart rate (HR) in beats/min and systolic blood pressure (BP) in $\mathrm{mmHg}$ in a male wild-type (A) and a male Mas-deficient animal (B) for $16 \mathrm{~s}$. HRV and BPV, Heart rate and blood pressure variabilities, respectively. the impression could arise that the influence of Mas-deficiency on BPV is much lower than on HRV. However, sex-specific evaluation revealed a more distinctive picture.

All parameters of the time domain and non-linear dynamics showed clear differences, being significantly elevated in knockout males. This increase was not accompanied by changes in If or hf and was not measurable by standard spectral methods.

In female mice, the differences between knockout animals and the control group were not as clear as in male animals. However, the trends showed a decrease of basic variability (sdNN, shannon) and an increase of sympathetic tone (lfn, lf/hf) which was opposite to the effects in male mice.

The measurements of baroreflex sensitivity confirmed the sex-specific character of BPV, although the differences did not reach statistical significance. In male knockout animals we registered an increase of baroreflex sensitivity as well as an increased number of baroreflex activities as a consequence of increased BPV, while in female animals we observed a decrease of both parameters with reduced HRV.

What is the reason for the gender-specific differences in HRV and BPV between animals of different genotypes? There is obviously no difference in the expression level or distribution of the Mas protooncogene between male and female mice (data not shown). Interestingly, gender has been shown to be a main determinant of HRV also in humans (22-24). However, the physiological mechanisms linking sex to HRV are still elusive although a role of estrogens in this phenomenon has been suggested (25).

The impact of gender on cardiovascular variability points to the more general importance of genetic influences on these parameters. A genetic component in HRV has already been confirmed by twin studies in humans $(26,27)$. However, the genes involved have not yet been detected in humans. To this purpose, transgenic animal models have 
Table 1 - Parameters of heart rate variability (HRV) and blood pressure variability (BPV).

Parameters of HRV and BPV, summarized for control $(+/+)$ and knockout $(-/-)$ animals of both genders. Values are reported as means $\pm S D ; P$, statistical significance; n.s., nonsignificant.

\begin{tabular}{lcrcc}
\hline Parameter & Domain & \multicolumn{1}{c}{+ /+ } & \multicolumn{1}{c}{ P } \\
\hline sdNN & HRV & $17.08 \pm 5.55$ & $11.69 \pm 5.65$ & 0.012 \\
shannon & HRV & $2.67 \pm 0.38$ & $2.27 \pm 0.45$ & 0.006 \\
If/hf & HRV & $0.47 \pm 0.25$ & $1.07 \pm 1.03$ & 0.031 \\
Ifn & HRV & $0.30 \pm 0.11$ & $0.45 \pm 0.17$ & 0.005 \\
fwshannon & HRV & $2.50 \pm 0.49$ & $2.41 \pm 0.41$ & n.s. \\
wsdvar & HRV & $1.87 \pm 0.63$ & $1.45 \pm 0.83$ & n.s. \\
wpsum13 & HRV & $0.36 \pm 0.23$ & $0.25 \pm 0.25$ & n.s. \\
sdNN & BPV & $3.36 \pm 1.43$ & $4.08 \pm 1.60$ & n.s. \\
shannon & BPV & $1.63 \pm 0.33$ & $1.78 \pm 0.33$ & n.s. \\
If/hf & BPV & $3.07 \pm 3.24$ & $4.33 \pm 5.77$ & n.s. \\
Ifn & BPV & $0.63 \pm 0.20$ & $0.64 \pm 0.27$ & n.s. \\
fwshannon & BPV & $1.99 \pm 0.24$ & $2.31 \pm 0.31$ & 0.019 \\
wsdvar & BPV & $0.79 \pm 0.64$ & $1.13 \pm 0.56$ & n.s. \\
wpsum13 & BPV & $0.09 \pm 0.17$ & $0.13 \pm 0.14$ & n.s.
\end{tabular}

Table 2 - Parameters of heart rate variability (HRV) and blood pressure variability (BPV).

Parameters of HRV and BPV in control $(+/+)$ and Mas-deficient $(-/)$ animals specified by gender. Values are reported as means $\pm S D ; P$, statistical significance; n.s., nonsignificant.

\begin{tabular}{|c|c|c|c|c|c|c|c|}
\hline \multirow[t]{2}{*}{ Parameter } & \multirow[t]{2}{*}{ Domain } & \multicolumn{3}{|c|}{ Male } & \multicolumn{3}{|c|}{ Female } \\
\hline & & $+/+$ & $-1-$ & $\mathrm{P}$ & $+/+$ & $-1-$ & $\mathrm{P}$ \\
\hline SdNN & HRV & $15.76 \pm 6.47$ & $10.70 \pm 4.87$ & n.s. & $18.39 \pm 4.55$ & $12.35 \pm 6.31$ & 0.016 \\
\hline Shannon & HRV & $2.59 \pm 0.47$ & $2.19 \pm 0.52$ & n.s. & $2.75 \pm 0.25$ & $2.32 \pm 0.42$ & 0.016 \\
\hline If/hf & HRV & $0.48 \pm 0.32$ & $1.45 \pm 1.53$ & 0.023 & $0.46 \pm 0.16$ & $0.81 \pm 0.45$ & n.s. \\
\hline Ifn & HRV & $0.30 \pm 0.13$ & $0.49 \pm 0.19$ & 0.013 & $0.30 \pm 0.08$ & $0.41 \pm 0.14$ & n.s. \\
\hline Fwshannon & HRV & $2.49 \pm 0.55$ & $2.43 \pm 0.50$ & n.s. & $2.50 \pm 0.48$ & $2.40 \pm 0.37$ & n.s. \\
\hline wsdvar & HRV & $1.65 \pm 0.79$ & $1.44 \pm 0.85$ & n.s. & $2.10 \pm 0.34$ & $1.46 \pm 0.88$ & n.s. \\
\hline wpsum13 & HRV & $0.29 \pm 0.25$ & $0.25 \pm 0.28$ & n.s. & $0.43 \pm 0.19$ & $0.25 \pm 0.25$ & n.s. \\
\hline sdNN & BPV & $2.94 \pm 0.73$ & $5.15 \pm 1.75$ & 0.011 & $3.78 \pm 1.85$ & $3.36 \pm 1.05$ & n.s. \\
\hline shannon & BPV & $1.55 \pm 0.23$ & $1.97 \pm 0.29$ & 0.01 & $1.70 \pm 0.40$ & $1.64 \pm 0.29$ & n.s. \\
\hline If/hf & BPV & $2.67 \pm 1.88$ & $4.42 \pm 6.07$ & n.s. & $3.46 \pm 4.35$ & $5.85 \pm 6.62$ & n.s. \\
\hline Ifn & BPV & $0.66 \pm 0.16$ & $0.52 \pm 0.34$ & n.s. & $0.61 \pm 0.25$ & $0.72 \pm 0.19$ & n.s. \\
\hline fwshannon & BPV & $1.87 \pm 0.18$ & $2.36 \pm 0.39$ & 0.014 & $2.11 \pm 0.23$ & $2.28 \pm 0.26$ & n.s. \\
\hline wsdvar & BPV & $0.49 \pm 0.30$ & $1.38 \pm 0.57$ & 0.006 & $1.08 \pm 0.76$ & $0.96 \pm 0.50$ & n.s. \\
\hline wpsum13 & BPV & $0.02 \pm 0.02$ & $0.18 \pm 0.18$ & 0.003 & $0.15 \pm 0.22$ & $0.09 \pm 0.09$ & n.s. \\
\hline
\end{tabular}

Table 3 - Spontaneous baroreflex.

Spontaneous baroreflex in control (+/+) and Mas-deficient (-/-) animals of both genders. Values are reported as means $\pm S D$. There were no statistically significant differences.

\begin{tabular}{lrrrrr}
\hline & \multicolumn{3}{c}{ Males } & & \multicolumn{2}{c}{ Females } \\
\cline { 2 - 3 } \cline { 5 - 6 } & \multicolumn{1}{c}{$+/+$} & & & \multicolumn{1}{c}{$+/+$} & \multicolumn{1}{c}{$/-$} \\
\hline Averaged number & $9.4 \pm 5.2$ & $14.5 \pm 14.0$ & & $7.3 \pm 7.3$ & $4.9 \pm 5.0$ \\
Averaged slope & $2.3 \pm 2.1$ & $1.4 \pm 0.6$ & & $1.5 \pm 0.8$ & $1.4 \pm 0.9$
\end{tabular}


been employed successfully. Recently, the $\beta_{1}$-adrenergic receptor (28), the GTP-binding protein $\mathrm{G}_{\mathrm{s} \alpha}(29)$ and the muscarinicgated potassium channel GIRK4 (30) have been demonstrated to cause alterations in HRV when their expression was enhanced or ablated in transgenic or knockout mice, respectively. The Mas-deficient mice represent the fourth transgenic animal model analyzed in this respect.

Mas could influence HRV in different ways. First, it is thought to be involved in the signaling of AngII $(14,15)$ which by itself is an important regulator of BP and HR. In particular, the missing low-frequency fluctuations in the HRV and BPV tachograms indicate a reduction in the impact of angiotensins on cardiovascular regulation in Masdeficient mice. Secondly, Mas has been shown to influence neuronal activity since its ablation leads to a more sustained LTP in the hippocampus (16). Therefore, also neurons involved in the control of HR may be affected by the absence of Mas. Thirdly, it has recently been shown that Mas signals via pathways involving mitogen-activated protein kinases, like jnk and p38 kinase (31), which are also activated by adrenergic receptors via G-proteins (32). The modulation of the signal transduction of these proteins shown to have a role in HRV (29) might be one mechanism by which Mas affects HRV.

A reduced HRV together with an increased sympathetic tone, as found in Masdeficient animals, is predictive for an increased cardiac risk in human beings $(2,3)$. Further studies are needed to show whether this is also true in mice and whether Mas may be an interesting target for preventive drug treatment.

\section{References}

1. Wolf MW, Varigos GA, Hunt D \& Sloman J G (1978). Sinus arrhythmia in acute myocardial infarction. Medical J ournal of Australia, 2: 52.

2. Kleiger RE, Miller J P, Bigger J r J T \& M oss AJ (1987). Decreased heart rate variability and its association with increased mortality after acute myocardial infarction. American J ournal of Cardiology, 59: 256262.

3. Algra A, Tijssen J GP, Roelandt J RTC, Pool J \& Lubsen J (1993). Heart rate variability from 24-hour electrocardiography and the 2-year risk for sudden death. Circulation, 88: 180-184.

4. Bigger J r J T, Fleiss J L, Steinman RC, Rolnitzky LM, Kleiger RE \& Rottman J N (1992). Frequency domain measures of heart period variability and mortality after myocardial infarction. Circulation, 85: 164171.

5. Singh $N$, Mironov $D$, Amstrong PW, Ross AM \& Langer A (1996). Heart rate variability assessment early after acute myocardial infarction. Circulation, 93: 1388-1395.

6. Tsuji H, Larson MG, Venditti FJ , Manders ES, Evans J C, Feldman $C L \&$ Levy $D$ (1996). Impact of reduced heart rate variability on risk for cardiac events. Circulation, 94: 2850-2855.
7. Zuanetti G, Neilson JMM, Latini R, Santoro E, Maggioni AP \& Ewing DJ (1996). Prognostic significance of heart rate variability in post-myocardial infarction patients in the fibrinolytic era. Circulation, 94: 432-436.

8. Korpelainen J T, Sotaniemi KA, Huikuri HV \& Myllya W (1996). Abnormal heart rate variability as a manifestation of autonomic dysfunction in hemispheric brain infarction. Stroke, 27: 2059-2063.

9. Young D, Waitches G, Birchmeier C, Fasano O \& Wigler M (1986). Isolation and characterization of a new cellular oncogene encoding a protein with multiple potential transmembrane domains. Cell, 45: 711-719.

10. Bunnemann B, Fuxe $K$, Metzger $R$, Mullins J, Jackson TR, Hanley MR \& Ganten D (1990). Autoradiographic localization of mas proto-oncogene mRNA in adult rat brain using in situ hybridization. Neuroscience Letters, 114: 147-153.

11. Martin KA, Grant SGN \& Hockfield S (1992). The mas proto-oncogene is developmentally regulated in the rat central nervous system. Developmental Brain Research, 68: 75-82.

12. Metzger R, Bader $M$, Ludwig T, Berberich C, Bunnemann B \& Ganten D (1994). Ex- pression of the mouse and rat mas protooncogene in the brain and peripheral tissues. FEBS Letters, 357: 27-32.

13. Villar AJ \& Pedersen RA (1994). Parental imprinting of the Mas protooncogene in mouse. Nature Genetics, 8: 373-379.

14. J ackson TR, Blair AC, Marshall J , Goedert M \& Hanley MR (1988). The mas oncogene encodes an angiotensin receptor. Nature, 335: 437-440.

15. Ambroz C, Clark AJ L \& Catt KJ (1991). The mas oncogene enhances angiotensininduced $\left[\mathrm{Ca}^{2+}\right] \mathrm{i}$ responses in cells with pre-existing angiotensin II receptors. Biochimica et Biophysica Acta, 1133: 107111.

16. Walther $T$, Balschun $D$, Voigt J P, Fink $H$, Zuschratter W, Birchmeier C, Ganten D \& Bader M (1998). Sustained long-term potentiation and anxiety in mice lacking the Mas protooncogene. J ournal of Biological Chemistry, 273: 11867-11873.

17. Denny J B, Polan-Curtain J , Wayner J \& Amstrong DL (1991). Angiotensin II blocks hippocampal long term potentiation. Brain Research, 567: 321-324.

18. Wright J W \& Harding J W (1992). Regulatory role of brain angiotensins in the control of physiological and behavioral responses. Brain Research Reviews, 17: 
227-262.

19. Parlow J, Viale J P, Annat G, Hughson R \& Quintin L (1995). Spontaneous cardiac baroreflex in humans. Hypertension, 25: 1058-1068.

20. Voss A, Dietz R, Fiehring $H$, Kleiner $H J$, Kurths J , Saparin P, Vossing HJ \& Witt A (1993). High resolution ECG, heart rate variability and nonlinear dynamics: tools for high risk stratification. In: Computers in Cardiology. IEEE Computer Society Press, Los Alamitos, 261-264.

21. Voss A, Kurths J, Kleiner HJ, Witt $A$, Wessel N, Saparin P, Osterziel KJ , Schurath R \& Dietz R (1996). The application of methods of non-linear dynamics for the improved and predictive recognition of patients threatened by sudden cardiac death. Cardiovascular Research, 31: 419-433.

22. Ryan SM, Goldberger AL, Pincus SM, Mietus J \& Lipsitz LA (1994). Gender- and age-related differences in heart rate dynamics: are women more complex than men? J ournal of the American College of Cardiology, 24: 1700-1707.

23. Stein PK, Kleiger RE \& Rottman J N (1997). Differing effects of age on heart rate variability in men and women. American J ournal of Cardiology, 80: 302-305.
24. Umetani $K$, Singer $D H, M c C r a t y ~ R \&$ Atkinson M (1998). Twenty-four hour time domain heart rate variability and heart rate: relations to age and gender over nine decades. J ournal of the American College of Cardiology, 31: 593-601.

25. Huikuri HV, Pikkujamsa SM, Airaksinen KE, Ikaheimo MJ, Rantala AO, Kauma H, Lilja M \& Kesaniemi YA (1996). Sex-related differences in autonomic modulation of heart rate in middle-aged subjects. Circulation, 94: 122-125.

26. Busjahn A, Voss A, Knoblauch $H$, Knoblauch M, Jeschke E, Wessel N, Bohlender J , McCarron J, Faulhaber HD, Schuster H, Dietz R \& Luft FC (1998). Angiotensin-converting enzyme and angiotensinogen gene polymorphisms and heart rate variability in twins. American J ournal of Cardiology, 81: 755-760.

27. Voss A, Busjahn A, Wessel N, Schurath R, Faulhaber HD, Luft FC \& Dietz R (1996). Familial and genetic influences on heart rate variability. J ournal of Electrocardiology, 29 (Suppl): 154-160.

28. Mansier $\mathrm{P}$, Médigue $\mathrm{C}$, Charlotte $\mathrm{N}$, Vermeiren C, Coraboeuf E, Deroubai $E$, Ratner E, Chevalier B, Clairambault J, Carré F, Dahkli T, Bertin B, Briand P, Strosberg D \& Swynghedauw B (1996).
Decreased heart rate variability in transgenic mice overexpressing atrial ß1-adrenoreceptors. American J ournal of Physiology, 271: 1465-1472.

29. Uechi M, Asai K, Osaka M, Smith A, Sato $\mathrm{N}$, Wagner TE, Ishikawa $\mathrm{Y}$, Hayakawa $\mathrm{H}$, Vatner DE, Shannon RP, Homcy CJ \& Vatner SF (1998). Depressed heart rate variability and arterial baroreflex in conscious transgenic mice with overexpression of cardiac Gs $\alpha$. Circulation Research, 82: 416-423.

30. Wickman K, Nemec J, Gendler SJ \& Clapham DE (1998). Abnormal heart rate regulation in GIRK4 knockout mice. Neuron, 20: 103-114.

31. Zohn IE, Symons M, ChrzanowskaWodnicka M, Westwick JK \& Der CJ (1998). Mas oncogene signaling and transformation require the small GTP-binding protein Rac. Molecular and Cellular Biology, 18: 1225-1235.

32. Yamauchi J , Nagao $M$, Kaziro $Y \&$ Itoh $H$ (1997). Activation of p38 mitogen-activated protein kinase by signaling through $\mathrm{G}$ protein-coupled receptors. Involvement of $G ß \gamma$ nd $G \alpha q / 11$ subunits. Journal of Biological Chemistry, 272: 27771-27777. 